\title{
DA IMPORTÂNCIA DA APLICAÇÃO DO PRINCÍPIO DA MORALIDADE NA ADMINISTRAÇÃO PÚBLICA
}

\author{
THE IMPORTANCE OF IMPLEMENTING THE PRINCIPLE OF MORALITY \\ IN PUBLIC ADMINISTRATION
}

Vanessa Manganaro de Araújo Almeron ${ }^{1}$

\begin{abstract}
RESUMO: Visa o presente trabalho tecer algumas considerações sobre a importância de a Administração Pública e seus agentes atuarem na conformidade de princípios éticos, sobretudo, em conformidade com o princípio da moralidade administrativa. Também se objetiva esclarecer a diferença entre moralidade e legalidade administrativa, bem como demonstrar que o princípio da moralidade administrativa deve ser erigido como valor constitucional e vetor fundamental que rege as atividades do Poder Público, poder este que representa verdadeiro pressuposto de legitimação constitucional dos atos emanados do Estado. Por fim, demonstrar-se-á quais as conseqüências e responsabilidades advindas do desrespeito desse princípio.
\end{abstract}

Palavras chave: Administração; Moralidade; Infringência e Desrespeito; Responsabilidade.

\begin{abstract}
This work aims to make a few observations on the importance of the Government and its agents act in accordance to ethical principles, particularly, in accordance with the principle of good administration. It also aims to clarify the difference between morality and legality administrative as well as demonstrate that the principle of good administration should be erected as constitutional values and fundamental vector that governs the activities of the government, power that this represents true constitutional presumption of legitimacy of the actions emanating the State. Finally, it will show what the consequences and responsibilities resulting from the failure of principle.
\end{abstract}

Palavras chave: Administration; Morality; Violation and disrespect; Responsibility

\section{BREVES NOÇÕES HISTÓRICAS}

Uma das mais árduas tarefas dos que têm por mister aplicar normas jurídicas, seja na posição de julgador, seja na de administrador, diz respeito à aplicação dos princípios jurídicos.

"Princípios de uma ciência são proposições básicas, fundamentais, típicas, que condicionam todas as estruturações subseqüentes. Princípios, neste sentido, são os alicerces da ciência.”

\footnotetext{
1 Especialista em Direito Civil e Processual Civil pela Universidade Estadual de Londrina e Especialista em Ministério Público: Estado Democrático de Direito - Direito Administrativo pela Fundação Escola do Ministério Público do Estado do Paraná
} 
É o conceito de José Cretella Júnior (Revista de informação Legislativa, v. 97:7) (CRETELLA JR., pg. 61).

Como não poderia deixar de ser, o Direito Administrativo está informado por determinados princípios, alguns próprios, outros, porém, de ramos diversos do Direito, mas de tamanha importância. Isso porque sendo o Direito Administrativo de elaboração pretoriana e não codificado, os princípios representam papel relevante nesse ramo do Direito, permitindo à Administração e ao Judiciário estabelecer o necessário equilíbrio entre os direitos dos administrados e as prerrogativas da Administração.

Caminhando na seara dos princípios que regem o Direito Administrativo, destacamos neste trabalho a importância e existência do Princípio da Moralidade Administrativa, inserido pela primeira vez entre os princípios expressos na Constituição Federal de 1988 (SPITZCOVSKY, 2005, pg. 46).

Para elucidar o tema, cumpre distinguir brevemente Moral e Direito: ambos podem ser representados por círculos concêntricos, sendo o maior correspondente à moral, e o menor, ao direito. Licitude e honestidade seriam os traços distintivos entre o direito e a moral, numa aceitação ampla do brocardo segundo o qual non omne quod licet honestum este (nem tudo o que é legal é honesto). Dizia Aristóteles (ARISTÓTELES, 2002, p.41) que "nossas disposições morais nascem de atividades semelhantes a elas". É por essa razão que devemos atentar para a qualidade dos atos que praticamos, pois nossas disposições morais correspondem às diferenças entre nossas atividades, de modo que os legisladores tornam bons os cidadãos por meio de hábitos que lhes incutem, sendo os atos morais, sua referência.

O exame das funções do princípio da moralidade conduz, ainda que introdutoriamente, a referir o papel da principiologia no direito público. Este tema tem sido posto com cada vez mais freqüência na doutrina (ESSER, 1961; DWORKIN, 1989; CANOTILHO, 1991, pg. 171; GRAU, 1988), sendo fundamental a sua compreensão no campo do direito público até porque é este, um direito não codificado: justamente por não configurar certa concepção sistemática de "ordem e unidade" internamente considerada - como ocorria com o direito civil correspondente ao paradigma oitocentista e expresso nos códigos do final do século XIX e início deste (CANARIS, 1989; FRIEDMAN, 1975; KERCHOVE E OST, 1988) - no direito administrativo os conjuntos normativos hábeis à regulação punctual dos diversos campos de interesse público - por exemplo, o da reforma administrativa (DECRETO-LEI N²00/67), o das licitações e contratos, os estatutos que definem o regime jurídico dos servidores (LEI No 8.666/93), os que sancionam certas condutas dos agentes públicos que caracterizam atos de improbidade (LEI 
FEDERAL $N^{\circ}$ 8.429/92) ou os que instrumentalizam a conduta dos cidadãos em face de atos administrativos lesivos, entre outros, - necessitam articular-se entre si, conexionando-se com a Constituição. As dificuldades que aí se põem decorrem, de um lado, da fluidez do próprio termo "moralidade" (LEI No 4.717/65), vinculando-se, de outro, a certa perplexidade quanto às funções do princípio na ordem prático-jurídica.

Antônio José Brandão (RDA 25:454) faz um estudo da evolução da moralidade administrativa, mostrando que foi no direito civil que a regra moral primeiro se imiscuiu na esfera jurídica, por meio da doutrina do exercício abusivo dos direitos e, depois, pelas doutrinas do não-locupletamento à custa alheia e da obrigação natural (FRANÇA, 1999). No âmbito do Direito Administrativo, o tema surge quando se começa a discutir, no âmbito jurisdicional, sobre o desvio de poder.

Até a entrada em vigor da atual Constituição (05 de outubro de 1988), princípios jurídicos de exponencial relevância para a ação administrativa como os da legalidade e da impessoalidade da conduta, o da ampla publicidade dos atos administrativos, o da economicidade da gestão da coisa pública e o da moralidade administrativa, ou vinham dispersos nos variados conjuntos normativos existente no ordenamento público brasileiro, ou, mesmo, eram tidos como pré-positivados, como se em "estado de latência" no ordenamento (ESSER, 1991, pg. 33). É certo que mesmo aí não se poderia pensar que, pelo fato de estarem dispersos no ordenamento, tais princípios fossem aplicáveis tão-somente no campo normativo onde inseridos. Forçoso é considerar, contudo, que a sua elevação ao status constitucional, sua alocação no pórtico do capítulo concernente à Administração Pública ou do seu controle externo (CONSTITUIÇÃO FEDERAL, ART. 37, CAPUT E ART. 70, CAPUT.), facilitaram a compreensão dos intérpretes e aplicadores da lei, porquanto melhor evidenciaram o caráter sistemático do ordenamento jurídico.

A pauta da moralidade administrativa, aqui a ser especificamente tratada, se espraia por toda a atividade jurídico-administrativa, impondo aos seus destinatários a atuar segundo princípios éticos (MELLO, 1992, pg. 61), daí derivando o aumento de deveres que lhes incumbem.

Celso Antônio Bandeira de Melo, ao tratar do princípio em comento, diz que "a Administração e seus agentes têm de atuar na conformidade de princípios éticos. Violá-los implicará violação ao próprio direito, configurando ilicitude que assujeita a conduta viciada a invalidação, porquanto tal princípio assumiu foros de pauta jurídica, na conformidade do artigo 37 da constituição" (MELLO, 2007, pg. 119). Moral e ética inspiram o sistema jurídico brasileiro e a 
dissociação entre o Direito e a Ética é inegavelmente descabida.

João Maurício Deotado (FRANÇA, 1999), argumentando sobre a impossibilidade de dissociar Direito e Ética, ressalta que essa separação somente é admissível como artifício metodológico e pragmático, não expressando qualquer realidade em si, ontológica, que pudesse vir a ser erigida em paradigma científico.

Certo é, que uma vez inseridos no ordenamento jurídico preceitos de ordem moral, estes passam a fazer parte integrante de validade das normas jurídicas, vinculando, portanto, a conduta do operador do direito. Nesse passo, caberá incumbirá sobremaneira ao princípio moral juridicizado conceder coerência e unidade ao Direito como sistema ético, preservando-o das injunções e tentativas de colonização por parte do econômico e do político no jurídico (FRANÇA, 1999).

Não se pode deixar de mencionar ainda que o princípio da moralidade administrativa está atrelado aos princípios da lealdade e boa-fé, devendo, portanto, a Administração proceder com sinceridade e lhaneza em relação aos administrados, proibindo-se qualquer comportamento eivado de malícia, produzido de maneira a confundir, dificultar ou minimizar os exercícios de direitos por parte dos cidadãos (FACHIN, 2008. pg 389-390).

A exemplo, cita-se a Lei $n^{0}$ 9.784/99, a qual prevê o princípio da moralidade no artigo $2^{\circ}$, caput, como um dos princípios a que se obriga a Administração Pública; e, no parágrafo único, inciso IV, exige "atuação segundo padrões éticos de probidade, decoro e boa fé", com referencia evidente aos principais aspectos da moralidade administrativa.

Celso Antônio, citando Márcio Cammarosano, sustenta que o princípio da moralidade não é uma remissão à moral comum, mas está reportado aos valores morais albergados nas normas jurídicas .

\section{MORALIDADE E LEGALIDADE: CONVERGÊNCIA E AUTONOMIA}

Com o texto do caput do art. 37 da Carta Magna, expurgou-se na doutrina e na jurisprudência administrativa qualquer dúvida quanto ao caráter normativo, e não apenas meramente informativo, do princípio da moralidade. Constitui-se como princípio constitucional geral do subsistema constitucional da administração pública, orientando e delimitando a atuação estatal no exercício da função administrativa. 
Vladimir da Rocha França ensina que:

O princípio constitucional geral da moralidade administrativa decorre da moralidade pública, implícita nos art. $5^{\circ}$, incisos LXVIII, LXIX e LXXIII, da Constituição vigente, entre os direitos e garantias fundamentais do cidadão, e, por razão do art. $60, \S 4^{\circ}$, do texto constitucional, elevada à condição de princípio constitucional fundamental (embora nem todas as cláusulas pétreas veiculem princípios fundamentais, eles são necessariamente cláusulas pétreas), sendo, por conseguinte, norma constitucional dotada de grau superior quando comparada aos demais princípios e regras constitucionais.

JuarezFreitas(FREITAS, 1997,pg.67-68)asseveraqueoconstituintebrasileiropretendeu conferir autonomia jurídica ao princípio da moralidade, o qual veda condutas eticamente inaceitáveis e transgressoras do senso moral da sociedade, a ponto de não comportarem condescendência.

Diz ainda: "Como princípio autônomo e de valia tendente ao crescimento, colabora, ao mesmo tempo, para reforço dos demais e para a superação da dicotomia rígida entre Direito e Ética, rigidez tão enganosa quanto aquela que pretende separar Direito e Sociedade, notadamente à vista dos avanços teóricos na reconceituação do sistema jurídico na ciência contemporânea” (FREITAS, 1997, pg. 67-68).

Maurice Hauriu, um dos principais sistematizadores da teoria da moralidade administrativa, preleciona que o conceito de moralidade não se trata de "moral comum", mas sim de uma moral jurídica, entendida como "o conjunto de regras de conduta tiradas da disciplina interior da Administração". A moral comum, conforme Haouriou, é imposta ao homem para sua conduta externa; a moral administrativa é imposta ao agente público para a sua conduta interna, segundo as exigências da instituição a que serve e a finalidade de sua ação: o bem comum (VASCONCELOS, 2003).

Assim como legalidade e finalidade, o princípio da moralidade também constitui pressuposto de validade dos atos administrativos, sem o qual a atividade pública pode ser considerada como ilegítima (CUNHA JR., 2006, pg. 16). Este princípio será havido como transgredido quando houver violação a uma norma de moral social que traga consigo menosprezo a um bem juridicamente valorado. Significa, portanto, um reforço ao princípio da legalidade, dando-lhe um âmbito mais compressivo do que normalmente teria.

A concepção clássica define o princípio da legalidade como aquele que determina ao administrador que sua conduta somente pode ocorrer quando, como e se estabelecida pelo legislador, procurando colocar a função administrativa subordinada à função legislativa . 
Analisando, porém, legalidade e moralidade, constata-se que os atos dissonantes do princípio da legalidade sempre importarão em violação à moralidade administrativa, concebida como o regramento extraído da disciplina interna da administração; a recíproca, no entanto, não é verdadeira. Justifica-se, já que um ato poderá encontrar-se intrinsecamente em conformidade com a lei, mas apresentar-se informado por caracteres externos em dissonância da moralidade administrativa, vale dizer, dos ditames de justiça, dignidade, honestidade, lealdade e boa-fé que devem reger a atividade estatal.

Importante frisar que, apesar de não guardar sinonímia com o princípio da legalidade, a moralidade administrativa apresenta uma relação de continência com o princípio da juridicidade, o qual abrange todas as regras e princípios norteadores da atividade estatal. Violado o princípio da moralidade administrativa, maculado estará o princípio da juridicidade, o que reforça a utilização deste como parâmetro para a identificação dos atos de improbidade (SOUSA, 2000). Assim, somente seria possível negar autonomia ao princípio da moralidade se à legalidade for dispensado um conceito amplo, abrangendo todos os valores jurisdicizados.

O princípio da legalidade exige a adequação do ato administrativo à lei, enquanto o da moralidade torna obrigatório que o móvel (MELLO, 2007, pg. 365) do agente e o objetivo pretendido estejam em harmonia com o dever de bem administrar. Ainda que os contornos do ato estejam superpostos à lei, será ele inválido se resultar de caprichos pessoais do administrador, afastando-se do dever de bem administrar e da consecução do bem comum.

A moralidade limita e direciona a atividade administrativa, tornando imperativo que os atos dos agentes públicos não subjuguem os valores que defluam dos direitos fundamentais dos administrados, o que permitirá a valorização e o respeito à dignidade da pessoa humana. Além de restringir o arbítrio, preservando a manutenção dos valores essenciais a uma sociedade justa e solidária, a moralidade confere aos administrados o direito subjetivo de exigir do Estado uma eficiência máxima dos atos administrativos, fazendo que a atividade estatal seja impreterivelmente direcionada ao bem comum (GARCIA, 2003).

\section{MORALIDADE E DESVIO DE PODER}

A Administração Pública possui sua própria moral, institucionalizada e que determina a conduta e desempenho da função administrativa a qual é conhecida como: moral administrativa. A aceitação de uma moral administrativa, inicialmente, fez-se através de um alargamento no 
raio de incidência do princípio da legalidade, passando o vício de moralidade a ser interpretado como vício de legalidade (FRANÇA, op. cit.).

Verifica-se no regime jurídico-administrativo a presença de um forte conteúdo ético ao se apreciar a finalidade da administração pública, qual seja, o bem estar da coletividade administrada. "Ilícito e imoral será todo ato administrativo que não for praticado no interesse da coletividade" (FRANÇA, op. cit.).

A imoralidade administrativa surgiu e se desenvolveu ligada à idéia de desvio de poder, pois se entendia que em ambas as hipóteses a Administração Pública se utiliza de meios lícitos para atingir finalidades metajurídicas irregulares. A imoralidade estaria na intenção do agente (DI PIETRO, 2008, pg. 73). Segundo Vladimir da Rocha França (FRANÇA, op. cit.):

\footnotetext{
"[...]quando imoral, o ato administrativo atenta contra a juridicidade que deve estar onipresente na conduta da administração pública, quebrando e distorcendo os fundamentos e diretrizes constitucionais, desprezando o dever de probidade imposto pela Constituição de 1988 ao agente público, e, por conseguinte, afastando a ação administrativa concreta da ética institucionalizada do regime jurídico que visa a administração pública concretizar[...]"
}

No desenvolvimento da aplicação da lei pelo administrador público, "aparecem atos que, não obstante se apresentarem como bons e legais, embutem, um desvio, uma vontade particular do administrador, em suma, uma violação do dever de exercício de uma boa administração e um atentado ao bem comum" (José Augusto Delgado). Infere-se daí o dever de bem administrar (NETO, op. cit., pg. 30) do Estado, o qual deve primariamente atender ao interesse público. A partir dessa construção percebe-se que a teoria do princípio da moralidade está diretamente vinculada aos freios a serem impostos aos agentes públicos na execução dos poderes discricionários, surgida e desenvolvida junto à idéia de desvio de poder.

Maria Sylvia Zanella Di Pietro analisando a questão defende que "com o objetivo de sujeitar ao exame judicial a moralidade administrativa é que o desvio de poder passou a ser visto como hipótese de ilegalidade, sujeita, portanto, ao controle judicial". E mais, diz: "ainda que, no desvio de poder, o vício esteja na consciência ou intenção de quem pratica o ato, a matéria passou a inserir-se no próprio conceito de legalidade administrativa".

Embora a Administração tenha o poder-dever de atuar o conteúdo desse específico dever não se esgota, pois, é preciso que sua ação se volte concretamente à satisfação de um "interesse" público; seu dever de administrar não se cumpre cabalmente se não for entendido como 
um dever de bem administrar. A eficácia de toda atividade administrativa está condicionada ao atendimento da lei e à satisfação do interesse público, não havendo liberdade nem prevalecendo a vontade pessoal do administrador (SILVA, 2000, pg. 430).

É justamente para que cumpra com este dever que é deferida, à Administração, a discricionariedade, dever-poder necessário ao desempenho da função administrativa. Sabe-se, entretanto, que o controle da discricionariedade - melhor dito, o controle de atos administrativos praticados no exercício do dever-poder da discricionariedade - apresenta peculiaridades. É justamente neste campo que o princípio da moralidade administrativa incide para aumentar o dever de boa administração, já que os princípios jurídicos se apresentam como mandados de otimização de condutas (COSTA).

O desvio de poder, em suas duas espécies denominadas excesso de poder e desvio de finalidade (MEIRELLES, pg. 108), efetivamente fixou a dimensão da teoria da moralidade administrativa como forma de limite à atividade discricionária da administração pública que, utilizando-se de meios lícitos, busca a realização de fins de interesses privados ou mesmo de interesses públicos estranhos às previsões legais (MELLO, pg. 56 e 64), ferindo, inclusive, o princípio da legalidade estrita (LENZA, 2007, pg. 707).

Nas lições de Celso Antônio Bandeira de Mello o desvio de finalidade se dá "quando o agente se serve de um ato para satisfazer finalidade alheia à natureza do ato utilizado". Assevera ainda, que o desvio pode manifestar-se de dois modos: a) "quando o agente busca una finalidade alheia ao interesse público" e b) “quando o agente busca uma finalidade - ainda que de interesse público - alheia a 'categoria' do ato que utilizou” (LENZA, 2007, pg. 707).

Nem todo o desvio de finalidade caracteriza afronta ao princípio da moralidade. Celso Antônio (LENZA, 2007, pg. 707) exemplifica da seguinte forma: a) no caso de punição a determinado funcionário, por intermédio de sua remoção, quando esta não é categoria punitiva, pode não ocorrer imoralidade, embora haja, incontroversamente desvio - isto é, o "desacordo objetivo entre a finalidade do ato e a finalidade da competência"; b) haverá, contudo, no exemplo referido, ferimento ao standard da moralidade, caso tenha o agente buscado finalidade pessoal ou de outrem e tenha agido para beneficiar amigo ou prejudicar inimigo, desatendendo o interesse público. Estarão, aí, claramente desatendidos os valores éticos que compõem o cerne conceitual do princípio da moralidade. A sua violação configurará ilicitude "que assujeita a conduta viciada à invalidação, porquanto tal princípio assumiu foros de pauta jurídica, na conformidade do art. 37 da Constituição". 
Por esta razão assegurava Hely Lopes Meirelles, na edição do Direito Administrativo Brasileiro imediatamente subseqüente a entrada em vigor da Constituição conduzir, tal princípio, o exame dos atos administrativos no plano de sua validade e não apenas ao de sua eficácia constituindo elemento plenamente sindicável pelos que têm por dever apreciar a legalidade, em amplo sentido, dos atos administrativos.

Nesse sentido, Fábio Medina Osório (OSÓRIO, 1998, pg. 155-156):

\begin{abstract}
A doutrina clássica desenvolveu mecanismos de controle de uma legalidade substancial dos atos administrativos e, nesse sentido, proporcionou espaço para o desenvolvimento dos princípios da legalidade e moralidade administrativas, aí incluída a possibilidade de se controlar mais amplamente conceitos jurídicos indeterminados, cuja definição era dispensada exclusivamente aos critérios subjetivos da Administração Pública!

A moralidade, no entanto, não se esgota na idéia de legalidade substancial, pois pode haver leis imorais que, por esse ângulo, se apresentem inconstitucionais. A imoralidade da lei não se deixa perceber pelo mero subjetivismo judiciário, pois aí haveria arbítrio. Percebe-se a imoralidade administrativa pelo conjunto dos princípios, de concepções doutrinárias, jurisprudenciais, hermenêuticas de um dado sistema que, em seu todo, repele determinadas soluções ou opções do legislador, por reputa-las inconstitucionais.

A moralidade administrativa abrange padrões objetivos de condutas exigíveis do administrador público, independentemente, inclusive, da legalidade e das efetivas intenções dos agentes públicos.
\end{abstract}

O controle sobre os atos dos agentes públicos deve ser rígido e intenso, o que permitirá um paulatino aperfeiçoamento da atividade estatal e, o que é mais importante, a necessária adequação dos agentes públicos aos valores próprios de um Estado Democrático de Direito, no qual o bem comum representa o pilar fundamental .

\title{
PROBIDADE ADMINISTRATIVA COMO COROLÁRIO DO PRINCÍPIO DA MORA- LIDADE ADMINISTRATIVA
}

Árdua é a tarefa de distinguir moralidade administrativa e probidade administrativa. Comumente se diz que são expressões sinônimas, tendo em vista que ambas se relacionam com a idéia de "honestidade" na Administração Pública. Quando se está diante da exigência de uma ou de outra não basta falar em legalidade formal, restrita, da atuação da Administração, é preciso ainda observar os princípios éticos, de lealdade, de regras que assegurem a boa administração e a disciplina interna da Administração Pública. 
O princípio da probidade administrativa representa uma especificação do princípio da moralidade administrativa ao vedar "a prática de atos desonestos e desleais para com a administração pública, praticados por agentes públicos ou terceiros no exercício de função pública (França RDP 1999, 63/71)" (FRANÇA, 1996). Para Vladimir da Rocha França (FRANÇA, 1996) enquanto a improbidade administrativa, atentado ao subprincípio da probidade administrativa, refere-se especialmente a conduta do agente público, acarretando o estabelecimento de sanções jurídicas para a repressão do desvio de comportamento do titular do múnus público, a imoralidade administrativa, que viola o princípio constitucional geral da moralidade administrativa, mais amplo e hierarquicamente superior, provoca a incompatibilidade jurídica entre o ato imoral e o regime jurídico-administrativo.

A improbidade administrativa, como ato ilícito, vem sendo prevista no direito brasileiro desde longa data, para os agentes políticos, enquadrando-se como crime de responsabilidade. Comparando moralidade e probidade, Maria Sylvia (PINHEIRO, 2009) afirma:

\footnotetext{
Como princípios, significam praticamente a mesma coisa, embora algumas leis façam referência às duas separadamente, do mesmo modo que há referência aos princípios da razoabilidade e da proporcionalidade como princípios diversos, quando este último é apenas um aspecto do primeiro.

No entanto, quando se fala em improbidade como ato ilícito, como infração sancionada pelo ordenamento jurídico, deixa de haver sinonímia entre as expressões improbidade e imoralidade, porque aquela tem um sentido muito mais amplo e muito mais preciso, que abrange não só atos desonestos ou imorais, mas também e principalmente atos ilegais. Na lei de improbidade administrativa (Lei n 8.429/92), a lesão à moralidade administrativa é apenas uma das inúmeras hipóteses de atos de improbidade revistos em lei.
}

Nos termos do artigo 85, V da Constituição da República, atentar contra a probidade na administração é hipótese prevista como crime de responsabilidade do Presidente da República, fato que enseja destituição do cargo. Além disso, os atos de improbidade administrativa dos servidores públicos imporão: a suspensão dos direitos políticos, a perda da função púbica, a indisponibilidade dos bens e o ressarcimento ao erário, na forma e gradação previstas em lei, sem prejuízo da ação penal cabível (art., 37, $4^{\circ}$ ). Infere-se, dessa forma, a estrita ligação entre o princípio constitucional da moralidade e o dever de probidade do agir administrativo.

A Lei n 1.079/50, anterior à Constituição de 1988, define os crimes de responsabilidade, prevendo em seu artigo $9^{\circ}$ os crimes contra a probidade administrativa; em alguns deles, há ofensa direta à lei, como na hipótese de infringência às normas legais sobre o provimento 
Da importância da aplicação do princípio da moralidade na administração pública.

dos cargos públicos; em outros, isso não ocorre, como na hipótese de omissão ou retardamento doloso na publicação de atos do Poder Executivo, na omissão de responsabilização dos subordinados por delitos funcionais e no procedimento incompatível com a dignidade, a honra e o decoro do cargo.

Analisando a regra insculpida no artigo 37, II da Constituição, a qual formula com extrema precisão a regra do acesso aos cargos públicos mediante prévio concurso de títulos e provas, percebe-se que o texto será inefetivo se estiverem os aplicadores da lei atados com uma concepção meramente formal do princípio da legalidade, não o articulando com os demais princípios e o afastando da pauta da moralidade. A análise de todo o procedimento, ou seja, os atos praticados desde a publicação do edital até a posse dos aprovados em concurso público deve ser analisada pelo Tribunal de Contas, o qual, na apreciação dos atos de admissão, levará em conta o exame das disposições administrativas reguladoras do procedimento competitório à vista do princípio da moralidade.

Depreende-se no caso dos concursos públicos, que o princípio da moralidade deve ser entendido como um comando que ordena sejam as regras editalícias conformadas com à pauta da moralidade, os deveres da impessoalidade, da publicidade, da razoabilidade, de conformidade entre objeto e ato, de motivação e de eficiência no agir administrativo (todos deveres de conduta que nascem da incidência de princípios, conduzindo à plena efetivação do dever fundamental de bem administrar).

O artigo 11 da Lei 8.429/92 diz configurar ato de improbidade administrativa ato "que atenta contra os princípios da administração pública qualquer ação ou omissão que viole os deveres de honestidade, imparcialidade, legalidade e lealdade às instituições”.

Nota-se, dessa forma, que bem maior deve ser a prudência do aplicador da lei à ocasião em que for enquadrada a conduta como de improbidade e também quando tiver de ser aplicada a penalidade. Imprescindível se torna nesse momento a aplicação dos princípios da razoabilidade, para aferir-se a real gravidade do comportamento, e da proporcionalidade, a fim de proceder-se à dosimetria punitiva. Fora desse contexto, a atuação da autoridade implicará em abuso de poder.

O texto do artigo em comento refere-se aos deveres de honestidade, imparcialidade, legalidade e lealdade às instituições, mas tal relação é nitidamente aleatória. Na verdade, o legislador disse menos do que queria. "O intuito é o da preservação dos princípios gerais da Administração Pública, como consta do título da sessão III da citada lei. A honestidade e a lealdade às instituições são associadas à moralidade e à probidade; a imparcialidade tem elo com a impessoalidade; e a legalidade já preexiste por si própria.” (CARVALHO FILHO, pg. 1025). 
O dispositivo citado constitui objeto da tutela à observância dos princípios constitucionais. "Com a positivação dos princípios, criaram-se tipos legais conformadores de improbidade administrativa. Assim, a violação de princípio configura-se fatalmente como violação do princípio da legalidade." (CARVALHO FILHO, pg. 1025).

\section{CONCLUSÕES}

A inclusão do princípio da moralidade administrativa na Constituição foi um reflexo da preocupação com a ética na Administração Pública e com o combate à corrupção e à impunidade no setor público.

A inserção do princípio da moralidade na CF/88 é coerente com a evolução do princípio da legalidade ocorrida no sistema jurídico de outros países, evolução essa que levou à instituição do Estado de Direito e do Estado Democrático de Direito, consagrado no preâmbulo da Constituição e em seu artigo $1^{\circ}$. Isso significou a ampliação do princípio da legalidade, que passou a abranger valores outros, entre eles os da razoabilidade, boa-fé, moralidade, economicidade e tantos outros hoje consagrados na doutrina, na jurisprudência e mesmo em regras expressas na Constituição e em normas infraconstitucionais. O objetivo foi o de reconquistar o conteúdo axiológico do direito, perdido em grande parte com o positivismo jurídico.

O princípio constitucional da moralidade administrativa configura um vigoroso instrumento à função de controle de legalidade. Atua positivamente, impondo à Administração Pública o dever de bem gerir e aumentando os demais deveres de conduta administrativa, tais como os de agir impessoalmente, garantir a ampla publicidade de seus atos, pautar-se com razoabilidade, motivar seus atos e decisões, agir com eficiência e observar a compatibilidade entre o objetivo de suas ações e o ato praticado para operacionalizar tal objetivo ou finalidade.

No sentido amplo, a legalidade (ou o Direito) absorveu todos os demais princípios, inclusive o da moralidade. No sentido restrito, a legalidade exige obediência à lei, enquanto a moralidade exige basicamente honestidade, observância da regras de boa administração, atendimento ao interesse público, boa-fé, lealdade.

Impõe, ainda, limites ao exercício da discricionariedade, permitindo a correção dos atos praticados em desvio de finalidade mediante o seu expurgo do mundo jurídico por meio da invalidação.

A presença da moral sempre se fará sentir na regra de direito, quer seja quando toma a própria forma desta, ou mesmo quando forneça o colorido da realidade social que haverá de 
ser regida pela norma de conduta, permitindo a sua integração e a consecução do tão sonhado ideal de justiça. Em que pese inexistir uma superposição total entre a regra de direito e a regra moral, em essência, não há uma diferença de domínio, de natureza e de fim entre elas; nem pode existir, porque o direito deve realizar a justiça, e a idéia de justo é uma idéia moral.

Identificada a existência de um regramento construído em valores morais e em normas jurídicas, a observância deste será tanto mais forte quanto for sua superfície de coincidência com os padrões de moralidade do grupamento que haverá de ser por ele regido. Correspondendo ao ideal moral, a norma será respeitada de forma voluntária, tendo-se um reduzido número de irresignações. Colidindo com os padrões de moralidade, haverá grande resistência na sua observância, o que comprometerá os próprios fins almejados com a sua edição, culminando com uma instabilidade social - situação que persistirá até que a norma consiga subjugar os ideais preexistentes, vindo a criar outros à sua imagem e semelhança.

\section{REFERÊNCIAS}

ARISTÓTELES. Ética a nicômaco, São Paulo: Martin Claret, 2002.

CARVALHO FILHO, José dos Santos. Manual de direito administrativo. 21. ed. Rio de Janeiro: Lúmen Júris, 2009

COSTA, Judith Martins. As funções do princípio da moralidade administrativa (o controle da moralidade na Administração Pública) TCE RS. Disponível em: http://www.tce.rs.gov.br/artigos/pdf/principio_moralidade.pdf. Acesso em: 16 mar. 2009.

CUNHA JUNIOR, Dirley da. Curso de direito administrativo. Bahia: Juspodvm, 2006.

DI PIETRO, Maria Sylvia Zanella de. Direito administrativo. São Paulo: Atlas, 2008.

FACHIN, Zulmar. Curso de direito constitucional. 3. ed. São Paulo: Método, 2008.

FRANÇA, Vladimir da Roça. Considerações sobre o controle de moralidade dos atos administrativos. Revista Trimestral de Direito Público, São Paulo, n. 27, p.58-74, 1999.

. Considerações sobre o controle de moralidade dos atos administrativos . Jus Navigandi, Teresina, ano 3, n. 34, ago. 1999. Disponível em: <http://jus2.uol.com.br/doutrina/texto. asp? $\mathrm{id}=338>$. Acesso em: 21 mar. 2009.

FREITAS, Juarez. O controle dos atos administrativos e os princípios fundamentais. São Paulo: Malheiros, 1997 
GARCIA, Emerson. A moralidade administrativa e sua densificação. Jus Navigandi, Teresina, ano 7, n. 86, 27 set. 2003. Disponível em: <http://jus2.uol.com.br/doutrina/texto.asp?id=4283>. Acesso em: 18 mar. 2009.

LENZA, Pedro. Direito constitucional esquemaizado. 11. ed. São Paulo: Método, 2007.

MEIRELLES, Hely Lopes. Direito administrativo brasileiro. 28. ed. São Paulo: Malheiros, 2003.

MELLO, Celso Antonio Bandeira de. Curso de direito administrativo. São Paulo: Malheiros, 2007.

. Elementos de direito administrativo. 3. ed. São Paulo: Malheiros, 1992

. Mandado de Segurança contra denegação ou concessão de liminar. Revista de Direito Público, São Paulo, n. 92, p. 55-61, 1989.

OSÓRIO, Fábio Medina. Improbidade administrativa. 2. ed. Porto Alegre: Síntese, 1998.

PINHEIRO, Letícia Barbosa. Responsabilidade civil do estado por atos legislativos. Disponível em: http://www.lfg.com.br 27 maio. 2008. Acesso em: 16 mar. 2009.

SILVA, José Afonso da. Curso de direito constitucional positivo. 19. ed. São Paulo: Malheiros, 2001.

SOUSA SEGUNDO, Lino Osvaldo Serra. A axiologia do conceito de moralidade administrativa tendo por base sua posição no sistema jurídico brasileiro. Jus Navigandi, Teresina, ano 5, n. 48, dez. 2000. Disponível em: <http://jus2.uol.com.br/doutrina/texto.asp?id=339>. Acesso em: 21 mar. 2009.

SPITZCOVSKY, Celso. Direito administrativo. 7. ed. São Paulo: Damásio de Jesus, 2005.

VASCONCELOS, Telmo da Silva. O princípio constitucional da moralidade e o nepotismo. Jus Navigandi, Teresina, ano 7, n. 66, jun. 2003. Disponível em: <http://jus2.uol.com.br/doutrina/ texto.asp?id=4101>. Acesso em: 18 mar. 2009. 